\title{
Flexible Microstrip Antenna for Skin Contact Application
}

\author{
Sudhir Shrestha, Mangilal Agarwal, Parvin Ghane, and Kody Varahramyan \\ Integrated Nanosystems Development Institute (INDI), Indiana University-Purdue University Indianapolis (IUPUI), \\ 723 West Michigan Street, Indianapolis, IN 46202, USA
}

Correspondence should be addressed to Mangilal Agarwal, agarwal@iupui.edu

Received 10 March 2012; Revised 4 June 2012; Accepted 4 June 2012

Academic Editor: Dalia N. Elshiekh

Copyright ( $) 2012$ Sudhir Shrestha et al. This is an open access article distributed under the Creative Commons Attribution License, which permits unrestricted use, distribution, and reproduction in any medium, provided the original work is properly cited.

\begin{abstract}
Microstrip antennas are finding a growing medical application in imaging, diagnosis, and treatment. This paper presents a flexible microstrip antenna that can be placed in contact with the human skin. The developed antenna is only $0.25 \mathrm{~mm}$ thick, has $32 \mathrm{~mm} \times 31 \mathrm{~mm}$ dimensions, and $-19 \mathrm{~dB}$ measured $\left|S_{11}\right|$ parameter at $2.45 \mathrm{GHz}$. A specific application of the antenna in microwave breast imaging is considered. Analytical results using simulation models and experimental results using skin phantoms are presented and discussed.
\end{abstract}

\section{Introduction}

Antennas have long been used in many medical applications including, microwave imaging, medical implants, hyperthermia treatments, and wireless wellness monitoring [1-9]. Reducing the size and complexity of the antennas used in these applications has been the primary objective of recent antenna research. Many of the above-mentioned medical applications still use bulky antenna systems which impede their efficiency and applicability despite high application potential. Microwave breast imaging can be taken as a very example [10]. The promises of microwave imaging in detecting early breast tumors without using any harmful radiation have drawn considerable attraction in the last decade [4]. However, antennas used in microwave breast imaging devices require to be immersed in intermediate matching liquid medium [11]. The use of such antennas makes the systems bulky, complicated, impractical, and expensive.

The planar and small form factor design of microstrip antennas has attracted growing medical applications [1215]. Microstrip antenna design reported for medical applications thus far use nonflexible substrates. This paper presents a microstrip antenna designed on a non conventional flexible substrate that can be placed on the skin. The flexibility and the ability to operate in contact with the skin improve the efficiency and practicality while reducing the form factor and cost. For example, the presented antenna in a microwave breast imaging device can remove the need for coupling liquid medium and thus enables the development of wearable breast imaging devices. The design methodology of the antenna, analytical results using simulation models in Ansoft high frequency simulation software (HFSS) [16], and experimental results using an in-house breast phantom are presented.

\section{Design Methodology}

The schematic of the proposed antenna is shown in Figure 1. A $0.25 \mathrm{~mm}$ thick flexible copper clad substrate was selected for the antenna design. With the substrate parameters given (shown in Figure 1(a)), a rectangular inset fed antenna at $2.45 \mathrm{GHz}$ with $50 \Omega$ input impedance was designed and optimized in Ansoft HFSS. A $1.5 \mathrm{~mm}$ skin layer (dielectric coefficient: $\varepsilon_{s}=39$ and conductivity: $\delta_{s}=1.1 \mathrm{~S} / \mathrm{m}$ [17]) was added on the top of the antenna model (Figure 1(a), not drawn in scale). Considering the skin as a layer of the substrate, the antenna was optimized to achieve lower return loss, higher gain, and better radiation pattern by varying the antenna sizes, adding a matching stub at the input port, and moving the feed port towards the edge to increase the impedance of the antenna. 


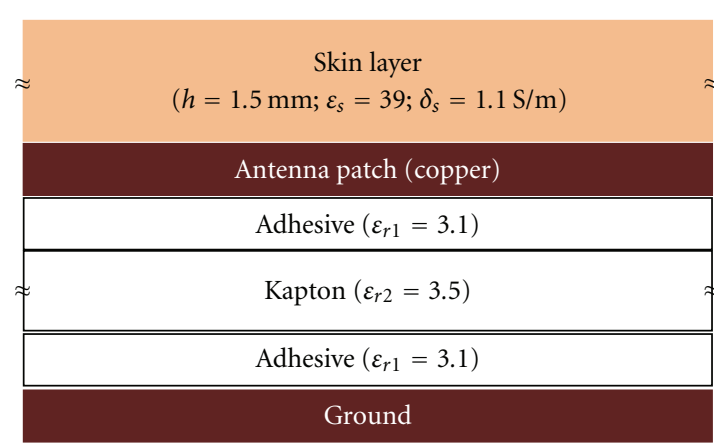

(a)

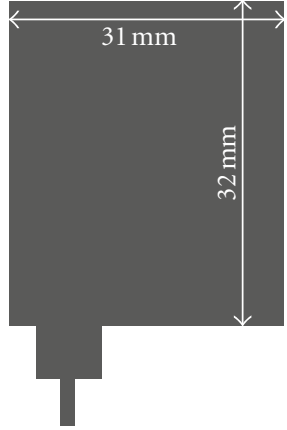

(b)

FIGURE 1: Schematics of (a) antenna-skin stack and (b) optimized antenna showing the matching stub at the input port (antenna dimensions: patch length: $32 \mathrm{~mm}$; patch width: $31 \mathrm{~mm}$ ).

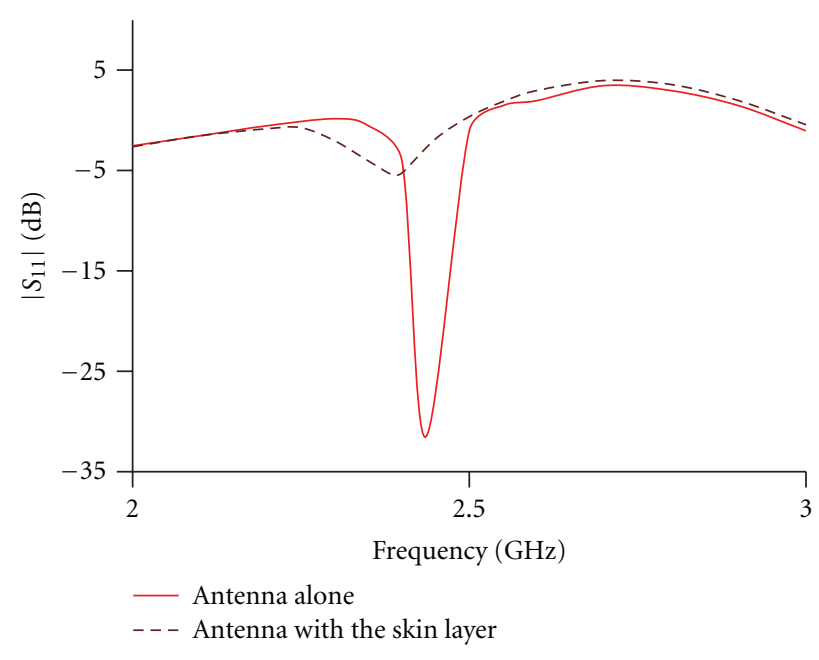

(a) $\left|S_{11}\right|$ parameter of the antenna with and without skin layer

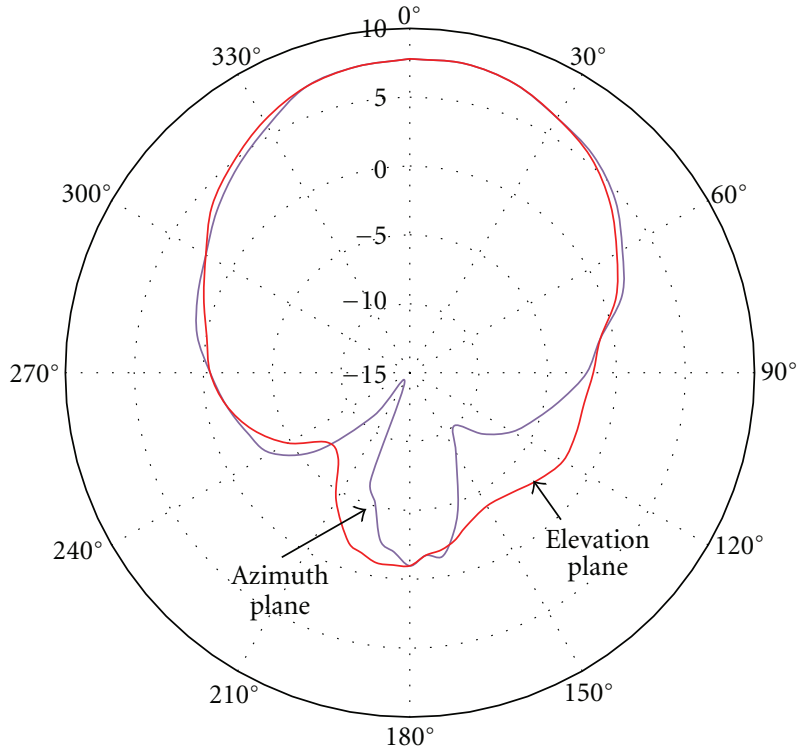

(b) Radiation pattern

FIGURE 2: Simulation results of the initial flexible microstrip antenna design before modifying for optimized skin contact operation.

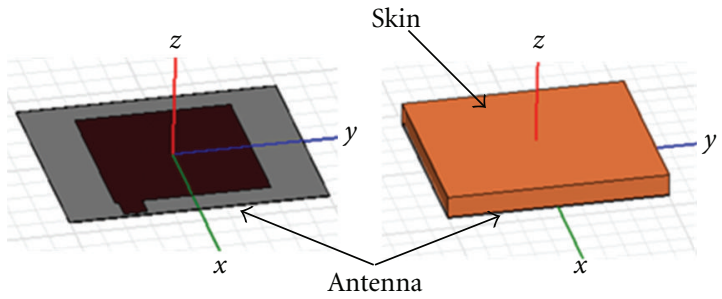

FIGURE 3: Images of antenna and antenna-skin simulation models.

\section{Results and Discussion}

Using the substrate parameters, an initial rectangular patch antenna was designed and simulated without any skin layer. The simulated $\left|S_{11}\right|$ parameter in $\mathrm{dB}\left(20 \log _{10}\left|S_{11}\right|\right.$, will be called as $\left|S_{11}\right|$ hereafter) and the radiation pattern of a flexible microstrip antenna are shown in Figure 2(a) (indicated as "antenna alone") and Figure 2(b), respectively. It is seen that the antenna has $-30 \mathrm{~dB}\left|S_{11}\right|$ at $2.42 \mathrm{GHz}$ with a good radiation pattern. A $1.5 \mathrm{~mm}$ thick skin model was then added on the top of the antenna model. As shown in Figure 1(a) (indicated as "antenna with the skin layer"), the $\left|S_{11}\right|$ of the antenna increased to $-5 \mathrm{~dB}$. It is observed that the ordinary antennas do not operate well when contacted with the skin. This requires the use of matching mediums between antenna and skin in many applications. For example, microwave breast imaging utilizes technique of immersing the antennas and the breast in liquid matching mediums [4].

In the next step, the microstrip antenna design was modified for an optimized operation with the skin layer on the top. The optimized antenna design is shown in Figure 1(b). The simulation models of the antenna with and without skin layer are shown in Figure 3. 


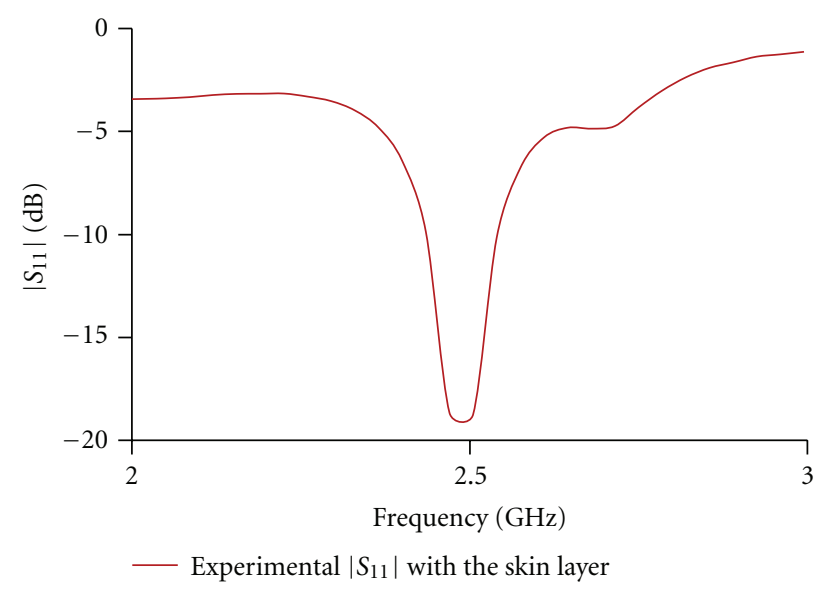

(a) Experimental $\left|S_{11}\right|$ of the antenna placed in contact with the skin phantom

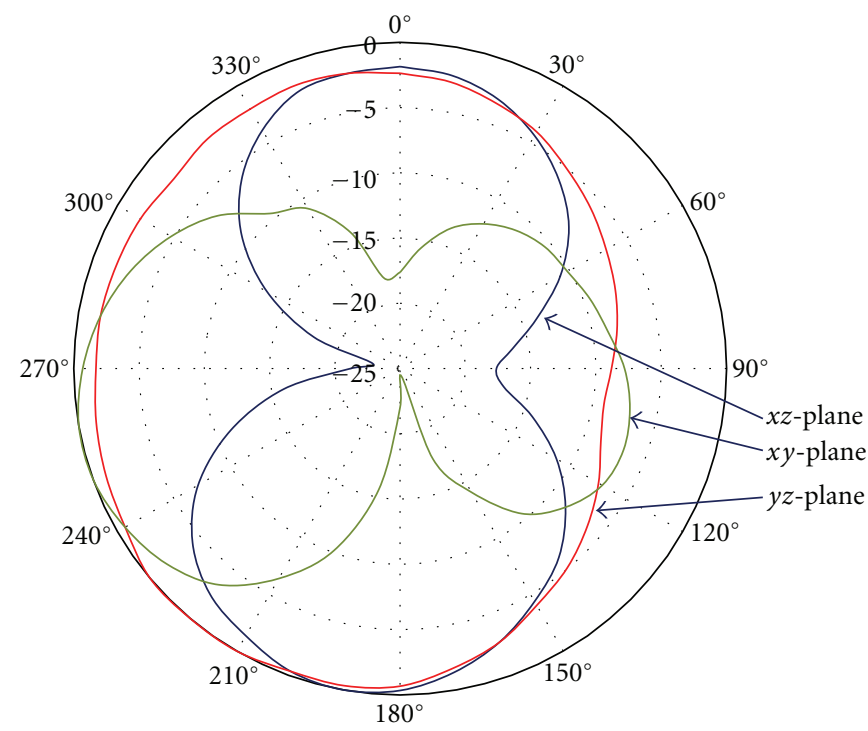

(c) Simulated $2 \mathrm{D}$ radiation patterns

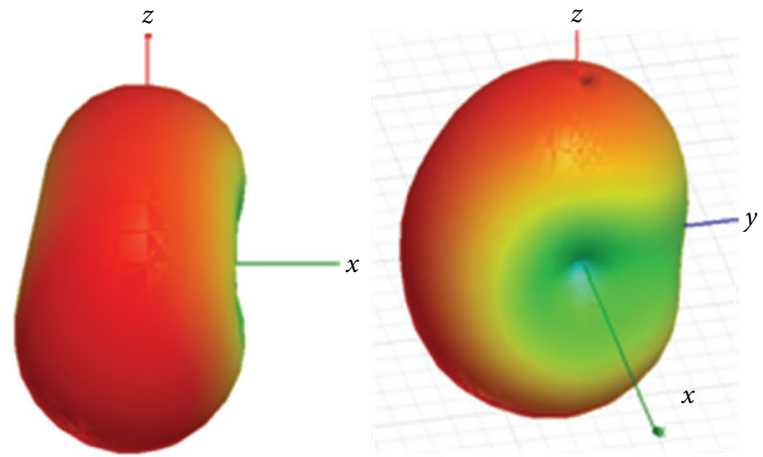

(b) Simulated 3D radiation patterns

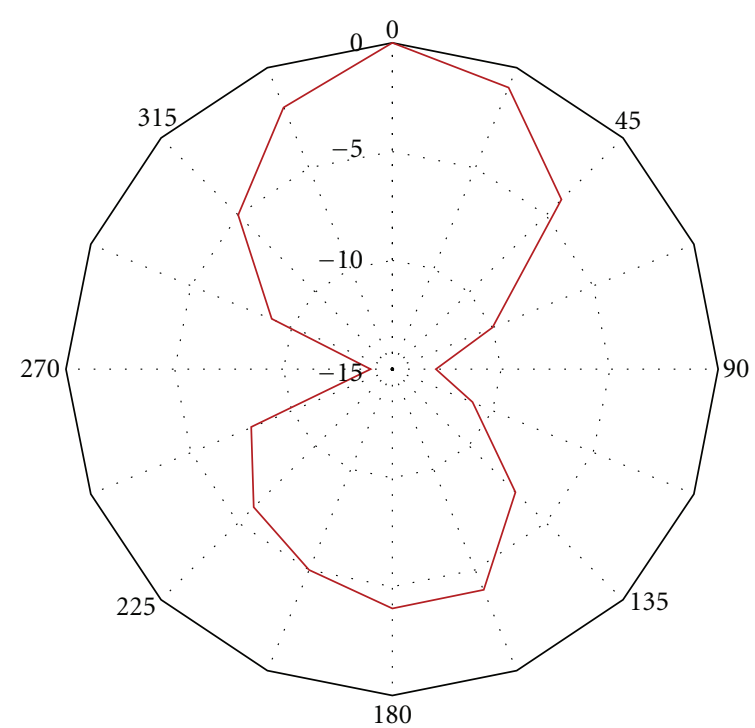

(d) Experimental radiation pattern of the antenna placed in contact with the skin phantom

FIGURE 4: Experimental and simulation results of the antenna placed in contact with the skin.

The designed antenna was fabricated on a flexible copper clad substrate using standard photolithography technique. First, the design was transferred onto a transparent mask. The copper substrate was cleaned, dried, and a $50 \mu \mathrm{m}$ positive photoresist (PR1813) was applied using a spinner. The substrate was heated for $2 \mathrm{~min}$ at $90^{\circ} \mathrm{C}$ and exposed to ultraviolet light through the mask. The substrate was subsequently developed in a developer solution, baked at $100^{\circ} \mathrm{C}$ for $15 \mathrm{~min}$, and etched. The antenna was cleaned, and a reverse polarity female SMA connector was added. A $1.5 \mathrm{~mm}$ skin phantom was made using $1: 1$ corn and water mixture cooked until it became jelly (adopted from [18]) and was placed on the top of the fabricated antenna. The experimental $\left|S_{11}\right|$ (measured using Rohde and Schwarz ZVL-13 vector network analyzer) is shown in Figure 4(a). The simulated $3 \mathrm{D}$ and $2 \mathrm{D}$ radiation patterns (in $x z, x y$, and $y z$-planes as indicated in Figure 3) are shown in Figure 4(b) and Figure 4(c), respectively. The experimental radiation pattern (on $x z$-plane) is shown in Figure 4(d).

To improve the radiation pattern of the antenna, a reflector configuration placed below the ground and separated by a $0.1 \mathrm{~mm}$ dielectric material, as shown in Figure 5(a), was considered. The design was simulated in Ansoft HFSS, and the improved radiation pattern is shown in Figure 5(b).

The simulation result shows a significant improvement (compared to Figure 4(b)) when a reflector configuration is added below the ground layer. A double-sided polyimide tape was used as the dielectric separator between ground and the reflector (indicated as "separator" in Figure 5(a)), and a copper tape was used as the reflector. The simulation result shows the possibilities of further improvement of the antenna for medical applications. 


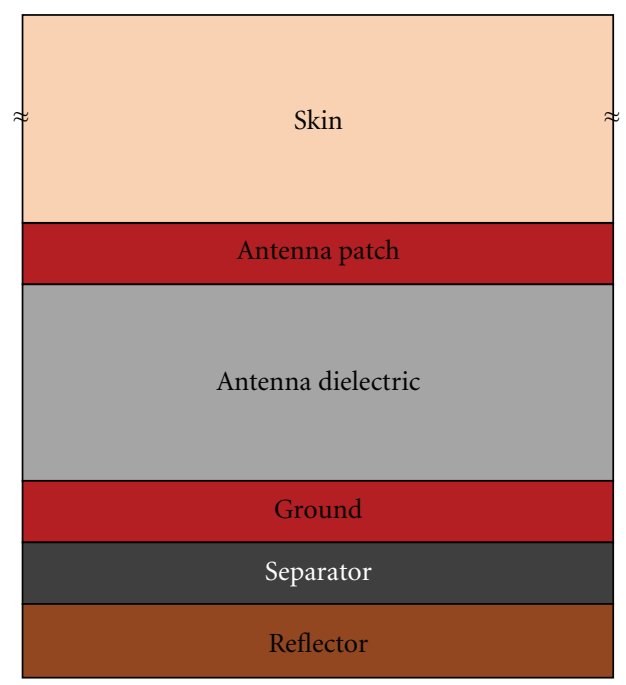

(a)

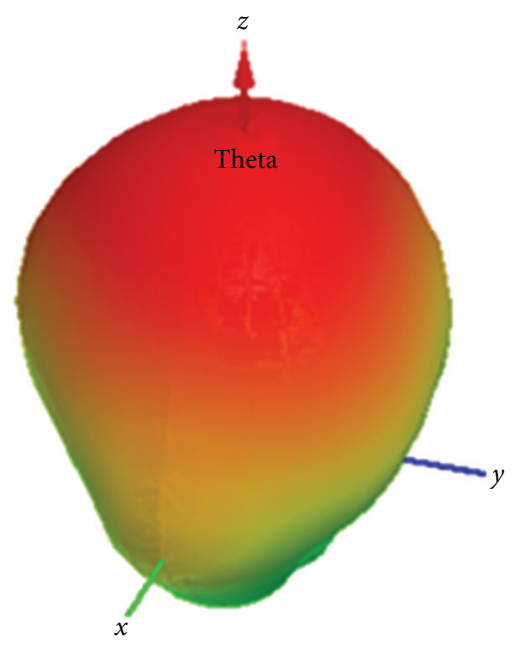

(b)

FIGURE 5: (a) Schematic showing the added reflector layer at the back of the ground and (b) 3D radiation pattern of the antenna with the reflector configuration.

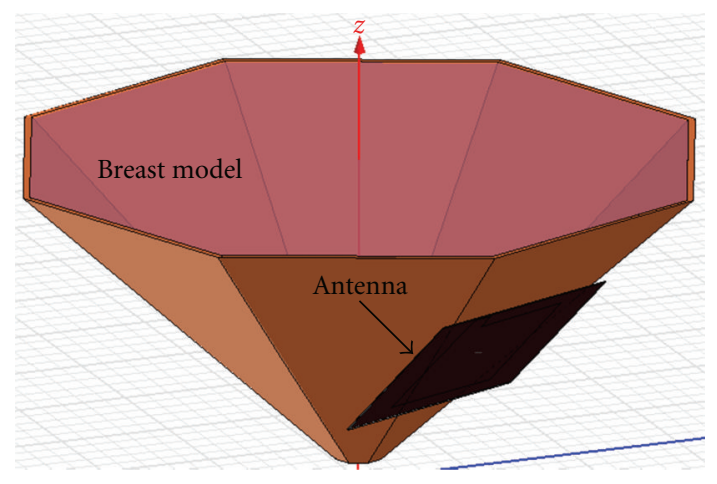

FIGURE 6: Simulation model in HFSS showing the breast and the antenna.

An application example of the antenna was considered in microwave breast imaging. Simulation model of the breast was developed in Ansoft HFSS with the antenna placed in contact with the skin model (Figure 6). The breast model was designed as a $10 \mathrm{~cm}$ wide and $5 \mathrm{~cm}$ high cone with eight facets. The breast skin was considered $1.5 \mathrm{~mm}$ thick layer with dielectric coefficient, $\varepsilon_{s}=39$, and conductivity, $\delta_{s}=$ $1.1 \mathrm{~S} / \mathrm{m}$ [17].

Many medical applications including microwave breast imaging require bending of the antenna. Experimentally, it was observed that the $\left|S_{11}\right|$ of the antenna was stable for bending up to 60 degrees. For a systematic study, an antenna simulation model was designed in Ansoft HFSS as shown in the inset of Figure 7. The model consisted of an antenna on a $10 \mathrm{~cm}$ wide and $5 \mathrm{~cm}$ high cone with multiple facets. The model was analysed for varying numbers of facets from 128 to 8 (representing increasing bending angles). As seen

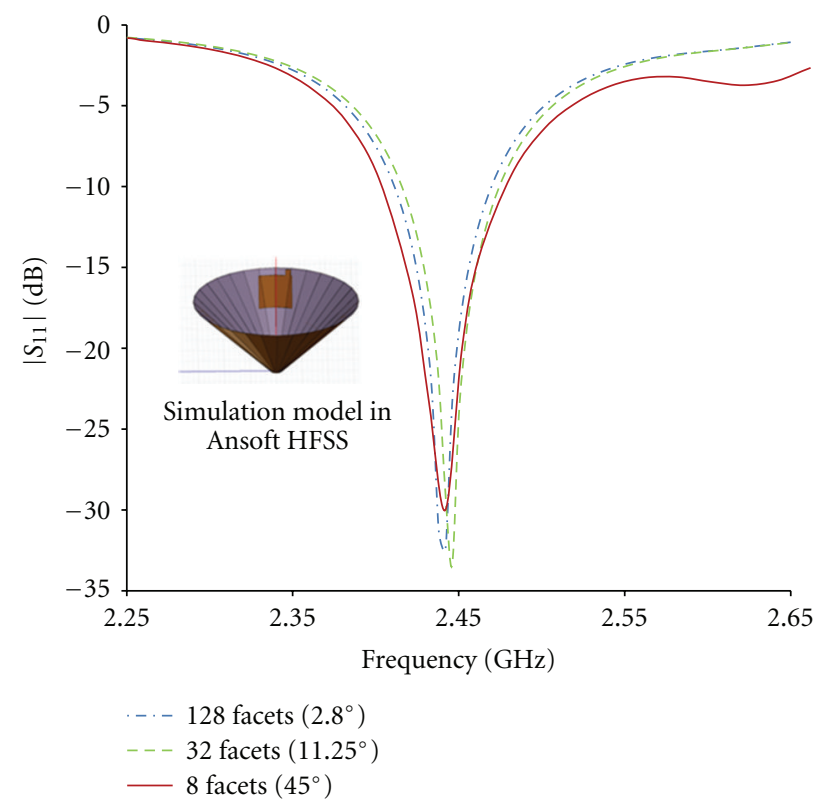

FIgURE 7: Simulation results showing $\left|S_{11}\right|$ of the antenna for 128, 32 , and 8 facets of the cone representing $2.8^{\circ}, 11.25^{\circ}$, and $45^{\circ}$ bending.

in Figure 7, the results for 128, 32, and 8 facets show no significant change in $\left|S_{11}\right|$ with the bending. The effect of placing multiple antennas was studied experimentally. An inhouse breast skin phantom was developed consisting of a $1.5 \mathrm{~mm}$ thick corn jelly placed on a cone mimicking breast skin. The antenna was fabricated through photolithography process and was placed on the phantom. The $\left|S_{11}\right|$ when one and four antennas were placed on the phantom were 


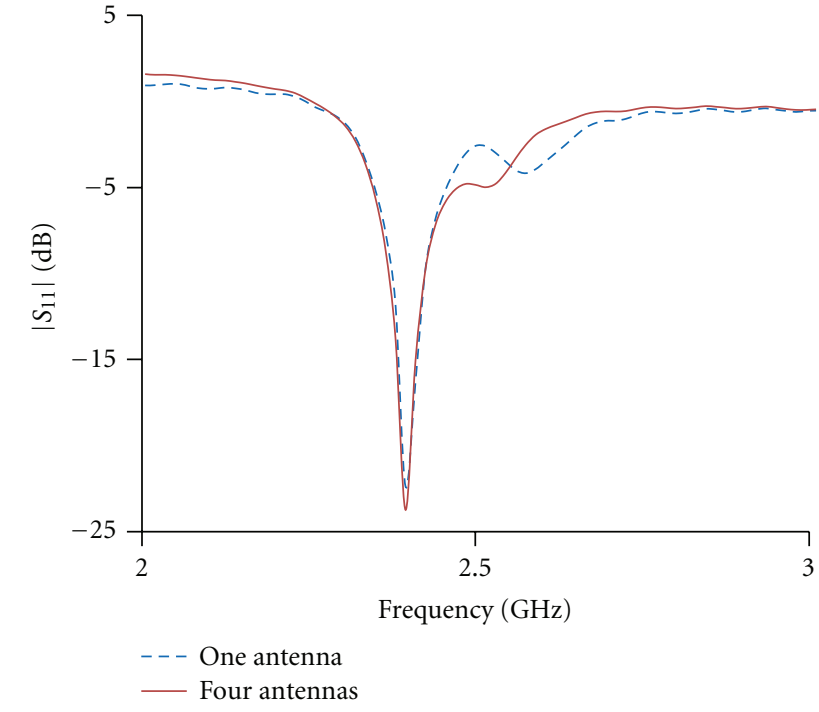

Figure 8: Experimental $\left|S_{11}\right|$ of the antenna when placed on breast phantom, when there was one antenna and four antennas.

measured. As shown in the Figure 8, no significant change was observed for one and four antennas.

\section{Conclusion}

A flexible microstrip antenna developed for skin contact application has been presented. Analytical results from simulation models and experimental results using in-house skin phantom have been presented and discussed. A specific application in microwave breast imaging has been presented with the help of simulation model and experimental testing. The presented planer flexible antenna can be used in wide varieties of medical applications, including, in developing wearable medical devices.

\section{Acknowledgment}

Acknowledgements are due to the Integrated Nanosystems Development Institute (INDI) for providing the laboratory facilities.

\section{References}

[1] J. C. Bolomey, "Recent European developments in active microwave imaging for industrial, scientific, and medical applications," IEEE Transactions on Microwave Theory and Techniques, vol. 37, no. 12, pp. 2109-2117, 1989.

[2] P. M. Meaney, K. D. Paulsen, A. Hartov, and R. K. Crane, "Microwave imaging for tissue assessment: initial evaluation in multitarget tissue-equivalent phantoms," IEEE Transactions on Biomedical Engineering, vol. 43, no. 9, pp. 878-890, 1996.

[3] L. Garnero, A. Franchois, J. P. Hugonin, C. Pichot, and N. Joachimowicz, "Microwave imaging-complex permittivity reconstruction by simulated annealing," IEEE Transactions on Microwave Theory and Techniques, vol. 39, no. 11, pp. 18011807, 1991.
[4] K. Planche and S. Vinnicombe, "Breast imaging in the new era," Cancer Imaging, vol. . 4, pp. 39-50, 2004.

[5] M. Mark, T. Bjorninen, Y. D. Chen et al., "Wireless channel characterization for mm-size neural implants," in Proceedings of the 32nd Annual International Conference of the IEEE Engineering in Medicine and Biology Society (IEEE-EMBS 10), pp. 1565-1568, September 2010.

[6] M. Converse, E. J. Bond, S. C. Hagness, and B. D. Van Veen, "Ultrawide-band microwave space-time beamforming for hyperthermia treatment of breast cancer: a computational feasibility study," IEEE Transactions on Microwave Theory and Techniques, vol. 52, no. 8, pp. 1876-1889, 2004.

[7] J. J. Lagendijk, "A microwave heating technique for the hyperthermic treatment of tumours in the eye, especially retinoblastoma," Physics in Medicine and Biology, vol. 27, no. 11, pp. 1313-1324, 1982.

[8] G. B. Gentili, V. Tesi, M. Linari, and M. Marsili, "A versatile microwave plethysmograph for the monitoring of physiological parameters," IEEE Transactions on Biomedical Engineering, vol. 49, no. 10, pp. 1204-1210, 2002.

[9] J. Montreuil and M. Nachman, "Multiangle method for temperature measurement of biological tissues by microwave radiometry," IEEE Transactions on Microwave Theory and Techniques, vol. 39, no. 7, pp. 1235-1239, 1991.

[10] R. K. Amineh, A. Trehan, and N. K. Nikolova, "TEM horn antenna for ultra-wide band microwave breast imaging," Progress In Electromagnetics Research B, no. 13, pp. 59-74, 2009.

[11] E. Alanen and I. V. Lindell, "Effect of skin in microwave detection of breast cancer," IEEE Transactions on Microwave Theory and Techniques, vol. 34, no. 5, pp. 584-588, 1986.

[12] P. Soontornpipit, C. M. Furse, and Y. C. Chung, "Design of implantable microstrip antenna for communication with medical implants," IEEE Transactions on Microwave Theory and Techniques, vol. 52, no. 8, pp. 1944-1951, 2004.

[13] S. Jacobsen, P. R. Stauffer, and D. G. Neuman, "Dualmode antenna design for microwave heating and noninvasive thermometry of superficial tissue disease," IEEE Transactions on Biomedical Engineering, vol. 47, no. 11, pp. 1500-1509, 2000.

[14] T. Karacolak, A. Z. Hood, and E. Topsakal, "Design of a dual-band implantable antenna and development of skin mimicking gels for continuous glucose monitoring," IEEE Transactions on Microwave Theory and Techniques, vol. 56, no. 4, pp. 1001-1008, 2008.

[15] R. Nilavalan, I. J. Craddock, A. Preece, J. Leendertz, and R. Benjamin, "Wideband microstrip patch antenna design for breast cancer tumour detection," IET Microwaves, Antennas and Propagation, vol. 1, no. 2, pp. 277-281, 2007.

[16] Ansoft HFSS, Ver. 12, Ansys Inc, http://www.ansys.com/.

[17] S. Padhi, F. Liu, B. K. Li, N. Shuley, and S. Crozier, "On the accurate modeling of a complex antenna for breast tumor detection using a hybrid MOM/FDTD approach," in Proceedings of the 29th Annual International Conference of IEEE-EMBS, Engineering in Medicine and Biology Society (EMBC '07), pp. 6636-6639, August 2007.

[18] G. N. Bindu, A. Lonappan, V. Thomas, C. K. Aanandan, and K. T. Mathew, "Dielectric studies of corn syrup for applications in microwave breast imaging," Progress In Electromagnetics Research, vol. 59, pp. 175-186, 2006. 

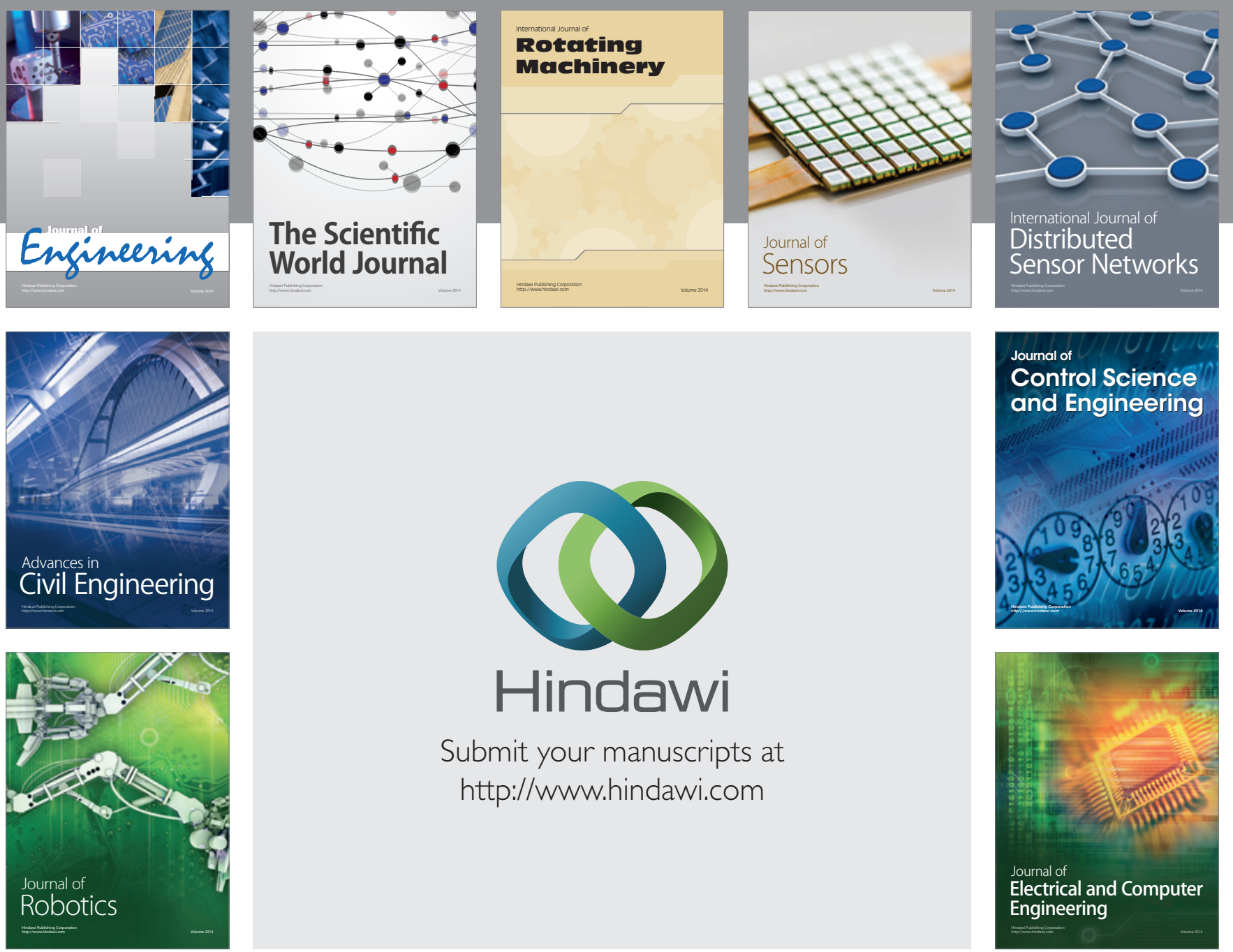

Submit your manuscripts at

http://www.hindawi.com
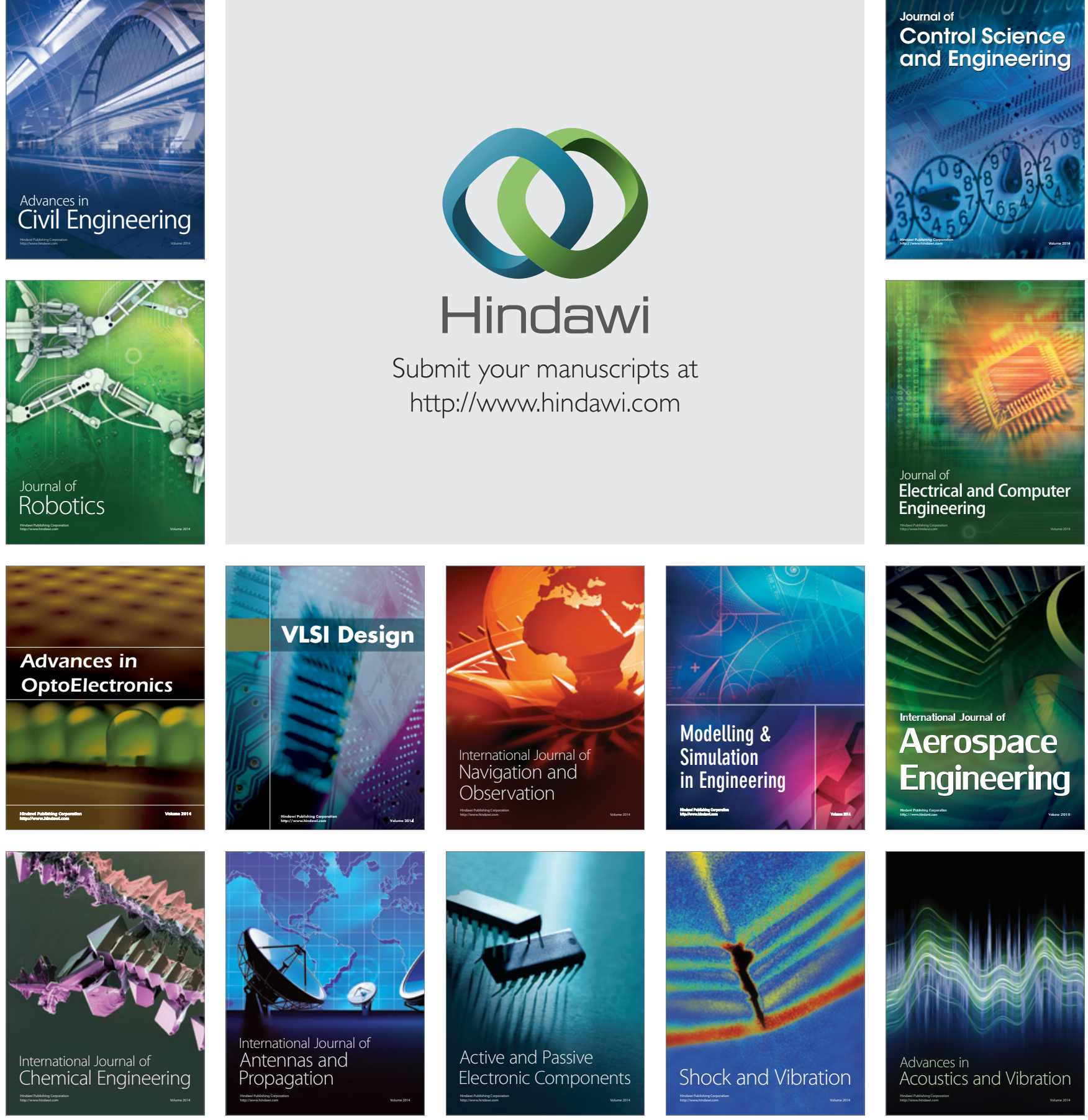